\title{
EXPERIÊNCIAS EM PROJETOS INTEGRADORES NO CURSO DE TECNOLOGIA EM SANEAMENTO AMBIENTAL DO IFPA CAMPUS \\ ITAITUBA
}

\author{
Vilma Ribeiro de Almeidal \\ Brendson Carlos Brito2 \\ Naum Pestana Collins ${ }^{3}$
}

\section{RESUMO}

Este artigo é resultado das experiências dos Projetos Integradores desenvolvidos no curso de Tecnologia em Saneamento Ambiental do Instituto Federal de Educação, Ciências e Tecnologia do Pará - Campus - Itaituba. Os projetos foram desenvolvidos em consonância com o planejamento dos conteúdos trabalhados nas disciplinas ofertadas, durante o segundo semestre letivo de 2017. A construção desta ação didático-pedagógica ocorreu de maneira interdisciplinar, voltada para a promoção do desenvolvimento de competências, valores, atitude, habilidades e conhecimentos necessários, que contribuam para a formação profissional dos futuros tecnólogos em Saneamento Ambiental e para o desenvolvimento tecnológico. Neste sentido, os trabalhos foram produzidos por meio de pesquisa bibliográfica e relato de experiência, durante a implantação e execução dos projetos. O objetivo deste artigo é favorecer o diálogo entre as disciplinas que integram o currículo, na perspectiva de contribuir para uma aprendizagem mais significativa e, sobretudo, que valorize a construção da autonomia intelectual dos estudantes, por meio da conjugação do ensino e pesquisa, estabelecendo assim, a articulação entre a teoria e a prática, os saberes e as habilidades do aluno. Os projetos tiveram como foco a interdisciplinaridade, uma ferramenta propícia para a inserção dos conteúdos que foram integrados à construção dos projetos. Dessa maneira, os Projetos Integradores são uma alternativa na construção de ensinoaprendizagem, capaz de agregar competências voltadas para a construção e formação dos saberes que contribuem para a efetivação da autonomia do aluno.

Palavras-chave: Projeto Integrador. Interdisciplinaridade. Competências.

1 Mestra em Educação (Pontifícia Universidade Católica de Goiás). Professora do Ensino Básico Técnico e Tecnológico do Instituto Federal do Pará. ORCID iD: https://orcid.org/00000002-1643-7595. E-mail: vilma.ribeiro@ifpa.edu.br

2 Mestre em Ciências Biológicas - Biologia de Água Doce Pesca e Interior (Instituto Nacional de Pesquisas da Amazônia). Professor do Ensino Básico Técnico e Tecnológico do Instituto Federal do Pará. ORCID iD: https://orcid.org/0000-0003-2561-6293. E-mail: brendson.brito@ifpa.edu.br

3 Mestrando em Agronomia (Universidade Estadual Paulista - Jabuticabal). Professor do Ensino Básico Técnico e Tecnológico do Instituto Federal do Pará. ORCID iD: https://orcid.org/0000-0001-6085-3820.E-mail: naum.colins@ifpa.edu.br 


\title{
EXPERIENCES IN INTEGRATING PROJECTS FOR THE ENVIRONMENTAL SANITATION TECHNOLOGY COURSE OF THE IFPA ITAITUBA CAMPUS
}

\begin{abstract}
This article is a result of the experiences of integrative projects developed in the Environmental Sanitation Technology course of the Federal Institute of Education, Science and Technology of Pará - Itaituba Campus. The projects were developed in consonance with the planning of the content of the subjects offered during the second semester of 2017. The construction of this pedagogical action took place in an interdisciplinary way directed to the promotion of the development of competences, values, attitude, abilities and knowledge necessary to contribute to the professional training of future technologists in Environmental Sanitation and to technological development. In this sense, the works were produced through a bibliographical research and experience report during the implementation of the projects. The aim of this article is to favor the dialogue between the disciplines that integrate the curriculum, with the perspective of contributing to a more meaningful learning that values the construction of students' intellectual autonomy through the conjugation of teaching and research, the articulation between theory and practice and the knowledge and skills of the student. The projects focused on interdisciplinarity, a propitious tool for the insertion of the content that was integrated into the construction of the projects. In this way, the integrating projects are an alternative pedagogical tool in the construction of teaching-learning processes, which is able to add competences focused on the construction of knowledge that contribute to the effectiveness of student autonomy.
\end{abstract}

Keywords: Integrative projects. Interdisciplinarity. Skills.

\section{EXPERIENCIAS EN PROYECTOS INTEGRADORES EN EL CURSO DE TECNOLOGÍA EN SANEAMIENTO AMBIENTAL DEL IFPA CAMPUS ITAITUBA}

\section{RESUMEN}

Este artículo es el resultado de las experiencias de los Proyectos Integradores desarrollados en el curso de Tecnología en Saneamiento Ambiental del Instituto Federal de Educación, Ciencias y Tecnología de Pará - Campus - Itaituba. Los proyectos fueron desarrollados en consonancia con la planificación de los contenidos trabajados en las disciplinas ofrecidas durante el segundo semestre lectivo de 2017. La construcción de esta acción didáctica-pedagógica ocurrió de manera interdisciplinaria dirigidas a la promoción del desarrollo de competencias, valores, actitudes, habilidades y conocimientos necesarios, que contribuyan a la formación profesional de los futuros tecnólogos en Saneamiento Ambiental y al desarrollo tecnológico. En este sentido, los trabajos fueron producidos por medio de investigación bibliográfica y relato de experiencia durante la implantación y ejecución de los proyectos. El objetivo de este artículo es favorecer el diálogo entre las disciplinas que integran el currículo, en la perspectiva de contribuir a un aprendizaje más significativo y, sobre todo, que valorice la construcción de la autonomía intelectual de los estudiantes a través de la conjugación de la

Revista Exitus, Santarém/PA, Vol. 9, № 3, p. 451 - 475, JUL/SET 2019. 
enseñanza e investigación, estableciendo así, la articulación entre la teoría y la práctica, los conocimientos y las habilidades del alumno. Los proyectos tuvieron como foco la interdisciplinaridad una herramienta propicia para la inserción de los contenidos que fueron integrados a la construcción de los proyectos. De esa manera, los Proyectos Integradores son una alternativa en la construcción de enseñanza-aprendizaje, capaz de agregar competencias dirigidas a la construcción y formación de los conocimientos que contribuyen a la efectividad de la autonomía del alumno.

Palabras clave: Proyecto Integrador. Interdisciplinariedad. Competencias.

\section{INTRODUÇÃO}

Este texto é resultado de reflexões durante o período de execução do Projeto Integrador, nas turmas do curso de Tecnologia em Saneamento Ambiental do Instituto Federal do Pará - Campus Itaituba. Essa ação pedagógica se deu a partir de um processo de ensino e aprendizagem que buscou estabelecer relações de modo interdisciplinar, utilizando metodologias de ensino, pautadas na construção individual e coletiva, que valorizassem a participação ativa e efetiva do aluno, como protagonista do processo educacional. Corroborando com Rajadell (2012, p. 113), que reconhece a importância das estratégias de ensino centradas no aluno como protagonista, não desmerecendo o papel do formador/professor que caminha ao seu lado, com o objetivo de dirigir e assegurar a efetividade da aprendizagem. É neste sentido, que conforme expresso no Projeto Pedagógico do Curso - PPC - de Tecnologia em Saneamento Ambiental do Instituto Federal de Educação, Ciência e Tecnologia do Pará (IFPA) Campus Itaituba, o Projeto Integrador é uma concepção de ensino e aprendizagem que pressupõe uma postura metodológica interdisciplinar a ser adotada pela instituição, envolvendo professores e alunos.

Essa proposta didática pedagógica tem como objetivo favorecer o diálogo entre as disciplinas que integram o currículo, na perspectiva de contribuir para uma aprendizagem mais significativa e, sobretudo, que valorize a construção da autonomia intelectual dos estudantes por meio da conjugação do ensino e pesquisa, estabelecendo assim a unidade entre teoria-prática. 
Dessa forma, a implementação de projetos integradores trabalhados nos $1^{\circ}, 2^{\circ}$ e $3^{\circ}$ períodos do Curso Superior de Tecnologia em Saneamento Ambiental visou, sobretudo, entrelaçar saberes que são apresentados de maneira específicas nas disciplinas desenvolvidos em cada período letivo. Assim, a proposta de trabalhar com Projeto Integrador se deu pelo fato, de poder articular os conteúdos e saberes rompendo com a fragmentação do conhecimento, estabelecendo uma relação entre o conhecimento teórico e prático.

\section{CONSTRUÇÃO DOS PROJETOS INTEGRADORES}

Os projetos integradores foram articulados na perspectiva metodológica interdisciplinar, envolvendo professores e alunos do curso de Tecnologia em Saneamento Ambiental, e teve como objetivo favorecer o diálogo entre as disciplinas que integraram o currículo do segundo semestre do ano de 2017, nas três turmas, com o foco de contribuir com a efetivação do ensino e aprendizagem e consequentemente de propiciar um espaço onde haja a busca pelo conhecimento. Entende-se que os alunos são os protagonistas no processo de construção do conhecimento, desta forma, a articulação dos temas para a elaboração dos projetos integradores foram pensados por eles próprios, em todas as três turmas do curso de Tecnologia em Saneamento Ambiental.

O processo de organização e elaboração dos projetos integradores foi acompanhado pelos professores, juntamente com os coordenadores responsáveis pela efetivação dos projetos. No que se refere ao processo inicial da construção da temática a ser trabalhada, os alunos foram levados a refletir acerca das diversas perspectivas que estariam envolvendo as disciplinas ofertadas naquele semestre, foi um período de discussão de ideias, mediante a gama de possibilidades que envolviam as disciplinas ofertadas.

A saber, na primeira turma, $1^{\circ}$ período - as disciplinas ofertadas foram: Avaliação de Impacto Ambiental; Reuso de Água; Projeto e Orçamento de Obras de Saneamento e Materiais para Sistemas e Instalações de Água e 
Esgoto. Na segunda turma, $2^{\circ}$ período: Topografia para Saneamento; Higiene e Segurança no Trabalho; Saúde Pública e Ambiental; Tratamento de Esgoto Sanitário; Hidráulica; Gestão Ambiental e Materiais para Sistema de Instalação de Água e Esgoto. E, por fim, na terceira turma, $3^{\circ}$ período: Tratamento de Efluentes Industriais; Instalações Prediais Hidro Sanitárias; Sistema de Recalque Água e Esgoto e Técnicas de Controle em Tratamento de Esgoto.

A partir deste levantamento de disciplinas ofertadas, optou-se por desenvolver um trabalho conjunto com os professores responsáveis por cada disciplina, os quais foram convidados a orientar os alunos em que a temática escolhida estivesse relacionada a sua disciplina. Neste sentido, compreendese que o Projeto Integrador é uma das alternativas capazes de aproximar, não somente os conteúdos interdisciplinarmente, mas também, de aproximação dos professores em busca de um objetivo comum, como a transformação social e ao mesmo tempo de compartilhar práticas pedagógicas, rompendo com o individualismo no ensino e fazendo com que este se torne mais efetivo, atraente e com resultados positivos quanto ao aprender a aprender. Nesta perspectiva, Candau (2007, p. 24) elucida que:

[...] a reflexão didática parte do compromisso com a transformação social, com a busca de práticas pedagógicas que tornem o ensino de fato eficiente (não se deve ter medo da palavra) para a maioria da população. Ensaia. Analisa. Experimenta. Rompe com uma prática profissional individualista. Promove o trabalho em comum de professores e especialistas.

A proposta didático-pedagógica foi coordenada por dois professores responsáveis pela efetivação dos projetos integradores, os quais buscaram realizar a integração entre os saberes constituídos com o saber em desenvolvimento, desta forma, buscou-se contextualizar a relação ativa do conhecimento, articulando as experiências significativas, relacionando-as com as aprendizagens consolidadas e aproximando-as com as experiências vividas em seus cotidianos. A aposta na elaboração, execução e apresentação dos Projetos Integradores se deu a partir das competências, em especial, a de aprender a participar ativamente, envolvendo os 
professores e alunos em um grupo de trabalho como bem enfocam Libâneo;

Oliveira; Toschi (2012, p. 529), que esta envolve um "conjunto de habilidades, entre as quais, relacionar-se bem com os colegas, ter disposição para a colaboração, saber expressar-se e argumentar com propriedade, saber ouvir, compartilhar interesses e motivações".

A partir desse esforço de consolidar conhecimentos, buscou-se desenvolver os projetos, seguindo as seguintes fases: a fase de intenção; preparação e planejamento; execução ou desenvolvimento e resultados finais, seguindo essas etapas para demonstrar a consonância com a execução do Projeto Pedagógico do Curso - PPC - que traz em seu escopo a definição para cada fase como explicitado abaixo na (Figura 1).

FIGURA 1 - Fases dos projetos integradores

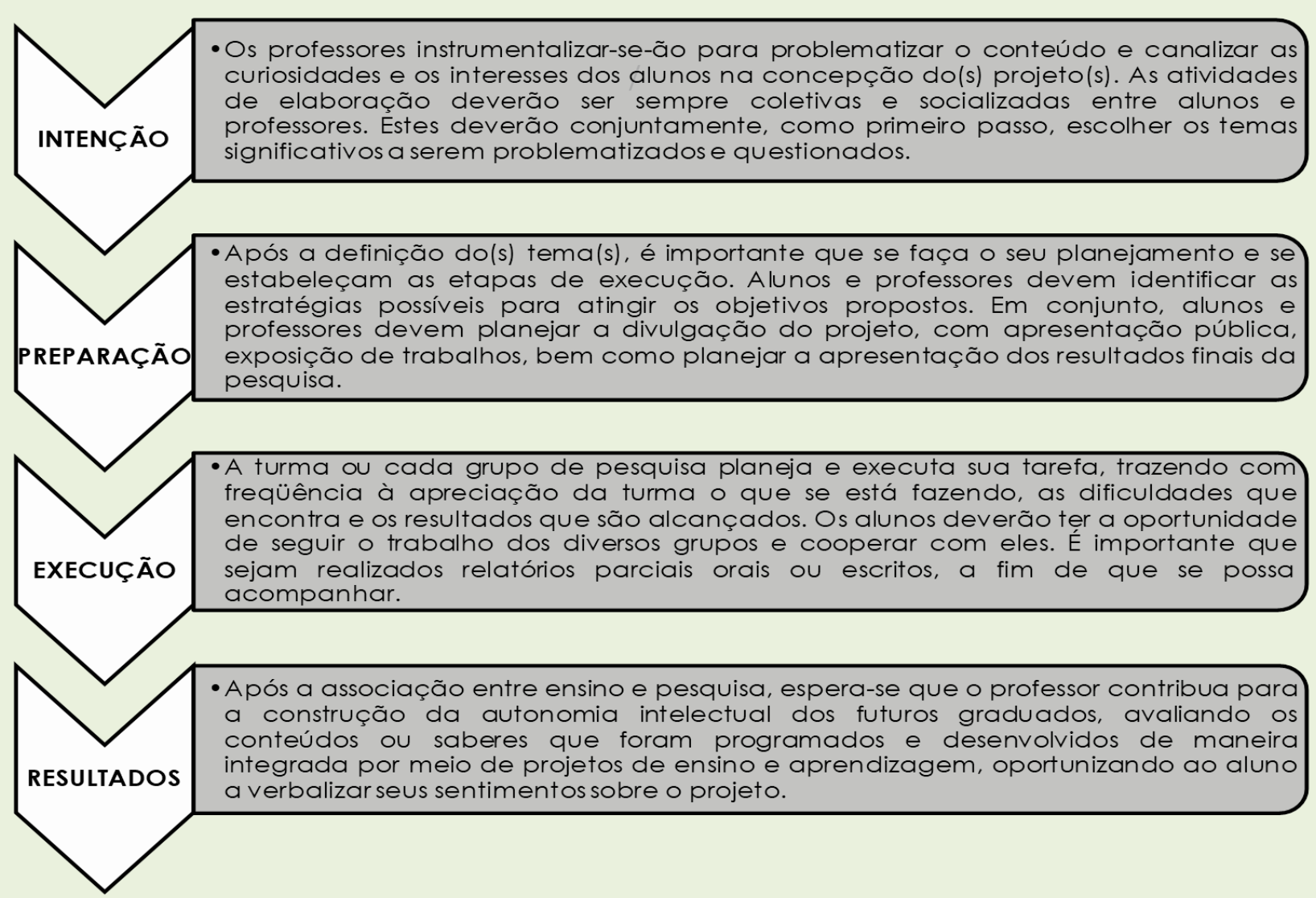

Fonte: Projeto Político Pedagógico do Curso em Tecnologia em Saneamento Ambiental, Instituto Federal do Pará-Campus Itaituba.

Ao abordar os passos para a realização dos projetos descrito no PPC do curso, infere-se que o papel do professor, nesse processo é de mediação 
da relação cognoscitiva entre o aluno e os conteúdos, como meio de organização do processo de aprendizagem. De acordo com Libâneo (2013, p. 56), "O ensino somente é bem-sucedido quando os objetivos do professor coincidem com os objetivos de estudo do aluno e é praticado tendo em vista o desenvolvimento de suas forças intelectuais". É neste processo de trocas que acontece o processo formativo, trilhado pelos caminhos de um processo interativo e interdisciplinar.

\section{INTERDISCIPLINARIDADE: um caminho metodológico}

Com a proposta de articular teoria, prática e saberes adquiridos, sendo eles, individuais e coletivos, com a perspectiva interdisciplinar que prime por uma formação dos futuros Tecnólogos em Saneamento Ambiental, com capacidades e competências. A perspectiva interdisciplinar surge no processo formativo para confirmar a proposta de romper com a fragmentação da educação, na forma de ensinar e construir conhecimentos, o que se propõe é incentivar e reafirmar a visão de conjunto que reverbera no saber instituído, que equalize os diversos tipos de conhecimentos como estratégias de ensino e aprendizagem.

Desta forma, faz se necessário entender a proposta da interdisciplinaridade na educação e em especial aplicada ao Projeto Integrador. A palavra interdisciplinaridade apresenta-se como um rico campo de questionamentos. O termo interdisciplinaridade pode propiciar diversos entendimentos e conter diferentes significados, por isso, Fazenda (2011, p. 51), relata que "o termo interdisciplinaridade não possui ainda um sentido único e estável. Trata-se de um neologismo, cuja significação nem sempre é a mesma e, cujo papel, nem sempre é compreendido da mesma forma". Embora as distinções terminológicas sejam inúmeras, o princípio delas é sempre o mesmo.

Varella (2010, p. 44-45) definiu a interdisciplinaridade como um movimento que possibilita o diálogo entre os seres humanos e os saberes. Isto impõe uma nova consciência, o ensino pautado na comunicação convergente dos programas de estudo das disciplinas, no diálogo entre os 
professores e alunos, em uma perspectiva de troca e enriquecimento de saberes individuais e experiências de vida, proporcionando a convergência para um conhecimento coletivo.

Enquanto que Fazenda et al. (2010, p. 32) afirma que a:

\begin{abstract}
interdisciplinaridade é um movimento que se aprende praticando, vivendo, não se ensina; portanto exige-se um novo posicionamento diante da prática educacional e da vida, pois a interdisciplinaridade é o motor de transformação, de mudança social, em que a comunicação, o diálogo e a parceria são fundamentais para que ela ocorra.
\end{abstract}

É nesta perspectiva que se estabeleceu a experiência com o Projeto Integrador no IFPA - Campus Itaituba, nas turmas de Tecnologia em Saneamento Ambiental, entendendo que a interdisciplinaridade não é uma panaceia que garantirá um ensino adequado, ou um saber unificado, mas um ponto de vista que permite uma reflexão aprofundada, crítica e salutar sobre o funcionamento do ensino. "É preciso integração, [...] num programa de estudos, é o conhecer e relacionar conteúdos, métodos e teorias, é integrar conhecimentos parciais e específicos em busca da totalidade sobre o conhecimento." Fazenda et al., (2010, p. 32).

É proposta de apoio aos movimentos da ciência e da pesquisa. É possibilidade de eliminação da dicotomia existente entre a atividade profissional e a formação escolar. É condição de volta ao mundo vivido e recuperação da unidade pessoal, pois o grande desafio "não é a reorganização metódica dos estudos e das pesquisas, mas a tomada de consciência sobre o sentido da presença do homem, da pessoa no mundo" (JAPIASSÚ, 1976, p. 31). Grifo nosso.

Para Fazenda (2002), a interdisciplinaridade pressupõe basicamente uma intersubjetividade, não pretende a construção de uma superciência, mas uma mudança frente ao problema do conhecimento, uma substituição da concepção fragmentada para a unitária do ser humano. Sendo assim, é preciso integrar o momento da interdisciplinaridade, em que há a organização das disciplinas, em um mesmo programa de estudos, é o conhecer e relacionar conteúdos, métodos e teorias, é integrar 
conhecimentos parciais e específicos em busca da totalidade sobre o conhecimento. Refere-se aqui, que a experiência com o Projeto Integrador permitiu a uma integração do conhecimento no movimento de (re)construção que, através de novos questionamentos, novas buscas, transforma o entendimento da realidade presente (FAZENDA et al. 2010, p. 38),

Neste mesmo entendimento, Fazenda (2003), elucida que a interdisciplinaridade se apoia na tríade, formada pelo sentido de ser, de pertencer e de fazer. Sendo assim, "A ação do educador será a de decifrar com o educando as coisas do mundo das quais ambos são participantes" (FAZENDA, 2003, p. 38). É nesta perspectiva que entende-se que a escola, se constitui como um local por excelência das relações, em especial, da relação ensino-aprendizagem, como afirma Valério (2009, p. 63), "é o lugar privilegiado para a instalação e ramificação das práticas interdisciplinares, pois é no ambiente escolar que se desenvolvem e se ampliam as habilidades e competências". É nesta interseção que se encontram professores e alunos, em um mesmo processo de busca, pesquisa, apropriação, criação de novos conhecimentos. Nesta direção, a autora relata que a interdisciplinaridade possibilita a abertura do olhar das pessoas, em direção a um mundo cada vez mais complexo e globalizado.

Diante dessa realidade, Marinho (2004, p. 54) enfoca que é necessário pensar no processo formativo de professores para a interdisciplinaridade e que isso, demanda pensar na identidade desses sujeitos, bem como nos saberes envolvidos nessa formação. Com certeza, não é tarefa fácil abrir-se para a interdisciplinaridade, porque mais do que estar disposto a aprender novos conteúdos escolares, significa estar preparado, a fim de se descortinar para o outro, em um processo de autoconhecimento e de aceitação da incompletude e da importância do outro na nossa essência. Neste aspecto, trabalhar com estudantes desenvolvendo Projeto Integrador, na perspectiva interdisciplinar, demanda abertura e competência do docente e compreensão do processo formativo que a interdisciplinaridade pressupõe. 
Fazenda (2002, p.15-16) focaliza quatro competências do professor interdisciplinar:

1.Competência intuitiva - sua característica principal é o comprometimento com um trabalho de qualidade - ele ama a pesquisa, pois ela representa a possibilidade da dúvida. O professor que pesquisa é aquele que pergunta sempre, que incita seus alunos a perguntar e a duvidar;

2.Competência intelectiva - a capacidade de refletir é tão forte e presente nele, que imprime esse hábito naturalmente a seus alunos. Analítico por excelência, privilegia todas as atividades que procuram desenvolver o pensamento reflexivo;

3.Competência prática - a organização espaço-temporal é seu melhor atributo. [...] Ama toda a inovação. Diferentemente do intuitivo, copia o que é bom, pouco cria, mas, ao selecionar, consegue boas cópias, alcança resultados de qualidade;

4.Competência emocional - ela trabalha o conhecimento sempre com base no autoconhecimento. [...] existe em seu trabalho um apelo muito grande aos afetos. Expõe suas ideias por meio do sentimento, provocando uma sintonia mais imediata. A inovação é sua ousadia maior.

Sendo assim, pode-se afirmar, de acordo com as Diretrizes Curriculares Nacionais Gerais para a Educação Básica que "a Interdisciplinaridade pressupõe a transferência de métodos de uma disciplina para outra. Ultrapassa-as, mas sua finalidade inscreve-se no estudo disciplinar da disciplina" (BRASIL, 2013, p. 184). Pela abordagem interdisciplinar efetivou-se o Projeto Integrador no IFPA - Campus Itaituba a busca de conhecimentos constitutivos de diferentes disciplinas, por meio da ação didáticopedagógica, mediada pela pedagogia dos projetos temáticos e a concretização de elaboração de artigos, a partir da pesquisa realizada. A interdisciplinaridade foi um marco referencial para a efetivação da proposta, que culminou com a apresentação dos resultados pelos alunos para a comunidade escolar.

\section{APLICAÇÃO DOS PROJETOS INTEGRADORES}

Após a definição dos temas (Tabela 1), os alunos, coordenadores e professores orientadores iniciaram as atividades de elaboração e execução dos projetos. Abaixo segue uma breve apresentação sobre os resultados 
obtidos em cada projeto e suas considerações acerca dos temas abordados.

TABELA 1 - Temas dos Projetos Integradores desenvolvidos pelas Turmas de Tecnologia em Saneamento Ambiental (TSA) 2014, 2015 e 2016, do IFPA Campus Itaituba

\begin{tabular}{|c|c|c|}
\hline PROJETOS & TEMAS DOS PROJETOS & TURMAS \\
\hline Projeto 1 & Métodos naturais: o uso do nim no combate de insetos & TSA-2014 \\
\hline Projeto 2 & $\begin{array}{l}\text { Avaliação do índice de desmatamento nos últimos cinco } \\
\text { anos na unidade de conservação flona do Jamanxin. }\end{array}$ & TSA-2014 \\
\hline Projeto 3 & $\begin{array}{l}\text { Compostagem de resíduos orgânicos: reaproveitamento de } \\
\text { resíduos domésticos em pequena escala }\end{array}$ & TSA-2014 \\
\hline Projeto 4 & $\begin{array}{l}\text { Percepção socioambiental dos moradores sobre as } \\
\text { atividades portuárias do distrito de Miritituba na cidade de } \\
\text { Itaituba/MA. }\end{array}$ & TSA-2015 \\
\hline Projeto 5 & $\begin{array}{c}\text { Análise das oportunidades recreativas no Parque Nacional } \\
\text { da Amazônia e comunidades do entorno. }\end{array}$ & TSA-2015 \\
\hline Projeto 6 & $\begin{array}{c}\text { Levantamento da percepção sobre as condições de saúde } \\
\text { e segurança dos trabalhadores de serviços gerais em } \\
\text { instituições de ensino na cidade de Itaituba-PA. }\end{array}$ & TSA-2016 \\
\hline Projeto 7 & $\begin{array}{l}\text { Condições de saneamento e os impactos causados a saúde } \\
\text { pública nos moradores de palafitas no município de ltaituba- } \\
\text { PA. }\end{array}$ & TSA-2016 \\
\hline Projeto 8 & $\begin{array}{l}\text { O gerenciamento de resíduos de serviço de saúde no } \\
\text { hospital municipal de Itaituba. }\end{array}$ & TSA-2016 \\
\hline Projeto 9 & $\begin{array}{l}\text { Revitalização do espaço beira rio: promovendo incentivo à } \\
\text { educação ambiental. }\end{array}$ & TSA-2016 \\
\hline
\end{tabular}

Fonte: Os autores.

\section{Projeto 1. Métodos naturais: o uso do nim no combate de insetos}

O resultado acerca da utilização de métodos naturais para o combate de insetos apresentou que a utilização do nim poderá ser uma alternativa viável, pois infere-se que além da questão econômica, com preços bem menores aos aplicados aos agrotóxicos, a sua utilização poderá beneficiar o meio ambiente.

O nim já é utilizado há mais de 2000 anos na Índia para "controle de insetos e pragas (mosca branca, minadoura, brasileirinho, carrapato, lagartas e pragas de grãos armazenados), nematoide, alguns 
fungos e bactérias" (MARANGONI; MOURA; GARCIA 2012, p.105). Sendo que os mesmos afirmam que "Existem mais de 413 espécies de insetos pragas de cultivos e criações sensíveis ao nim estudadas até 1995 por Schmuterer" (MARANGONI; MOURA; GARCIA, 2012, p.105).

Localizou-se no município de Itaituba uma propriedade rural onde $\circ$ agricultor afirma fazer uso da utilização do nim em sua propriedade e atesta que é bastante viável, dando resultados positivos (Figura 2).

FIGURA 2: Solução pronta: recipiente com o extrato aquoso do nim

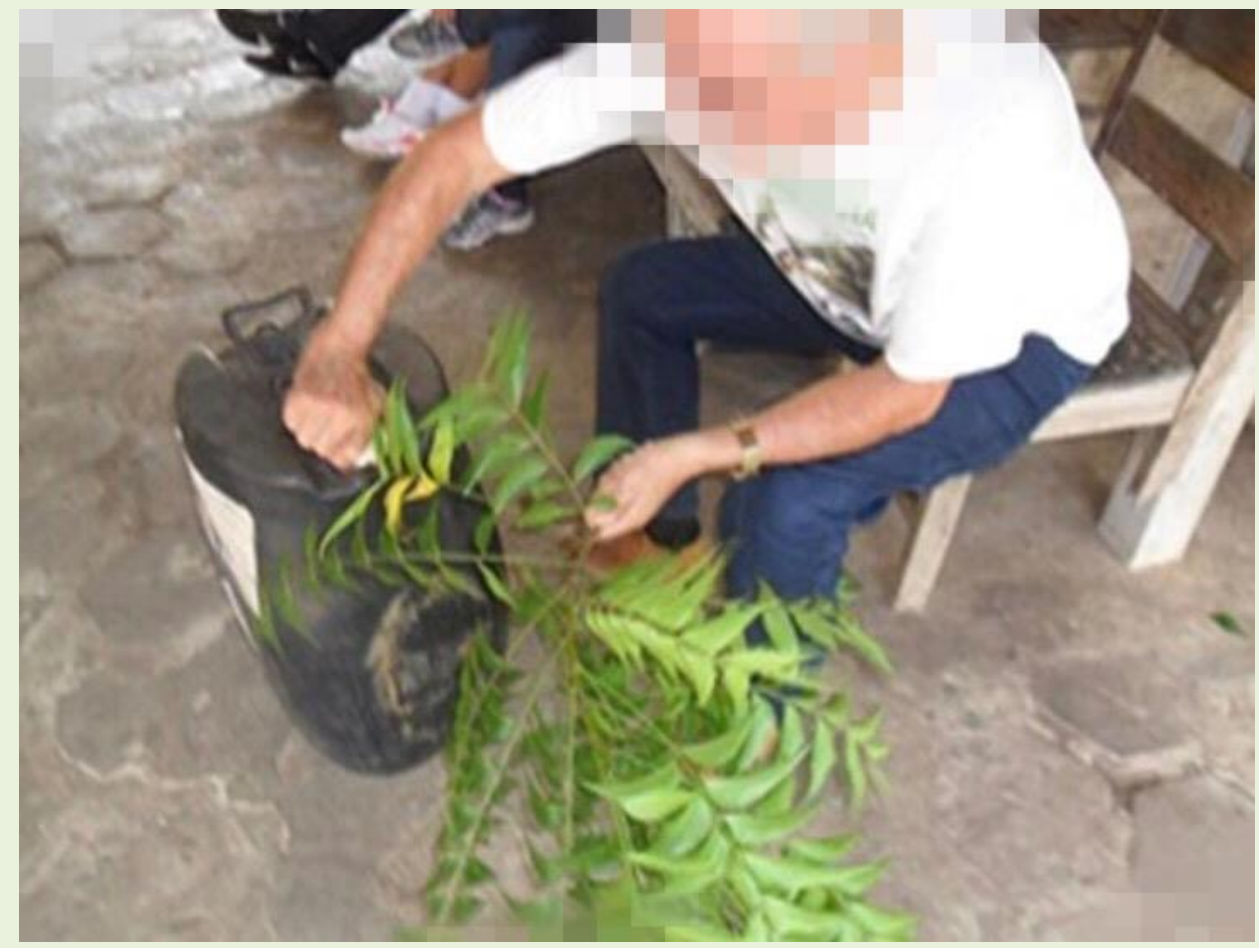

Fonte: Arquivo dos pesquisadores, 2017.

Projeto 2. Avaliação de índice de desmatamento nos últimos cinco anos na unidade de conservação flona do Jamanxim

A Floresta Nacional do Jamanxim, revela uma taxa de desmatamento médio, entre os anos de 2008 a 2015, conforme Figura 3.

Por outro lado, apesar dos esforços empreendidos para gestão e fiscalização, nesta unidade de conservação, ela manteve-se presente nos rankings das dez unidades protegidas mais desmatadas da Amazônia Legal nos últimos anos. 
A luta contra o desmatamento ilegal nas UC's brasileiras tem sido um constante desafio que tem se mostrado cada vez mais longe de ser superado, devido os inúmeros fatores como, por exemplo, a expansão da fronteira agropecuária e de projetos de infraestrutura.

FIGURA 3: Taxas de desmatamento nas Unidades de Conservação da Amazônia Legal entre 2008 e 2015 e sua participação (\%) no total do desmatamento na região

-Taxa de desmatamento anual nas UCs

\% do total do desmatamento na Amazônia que ocorreu em UCs

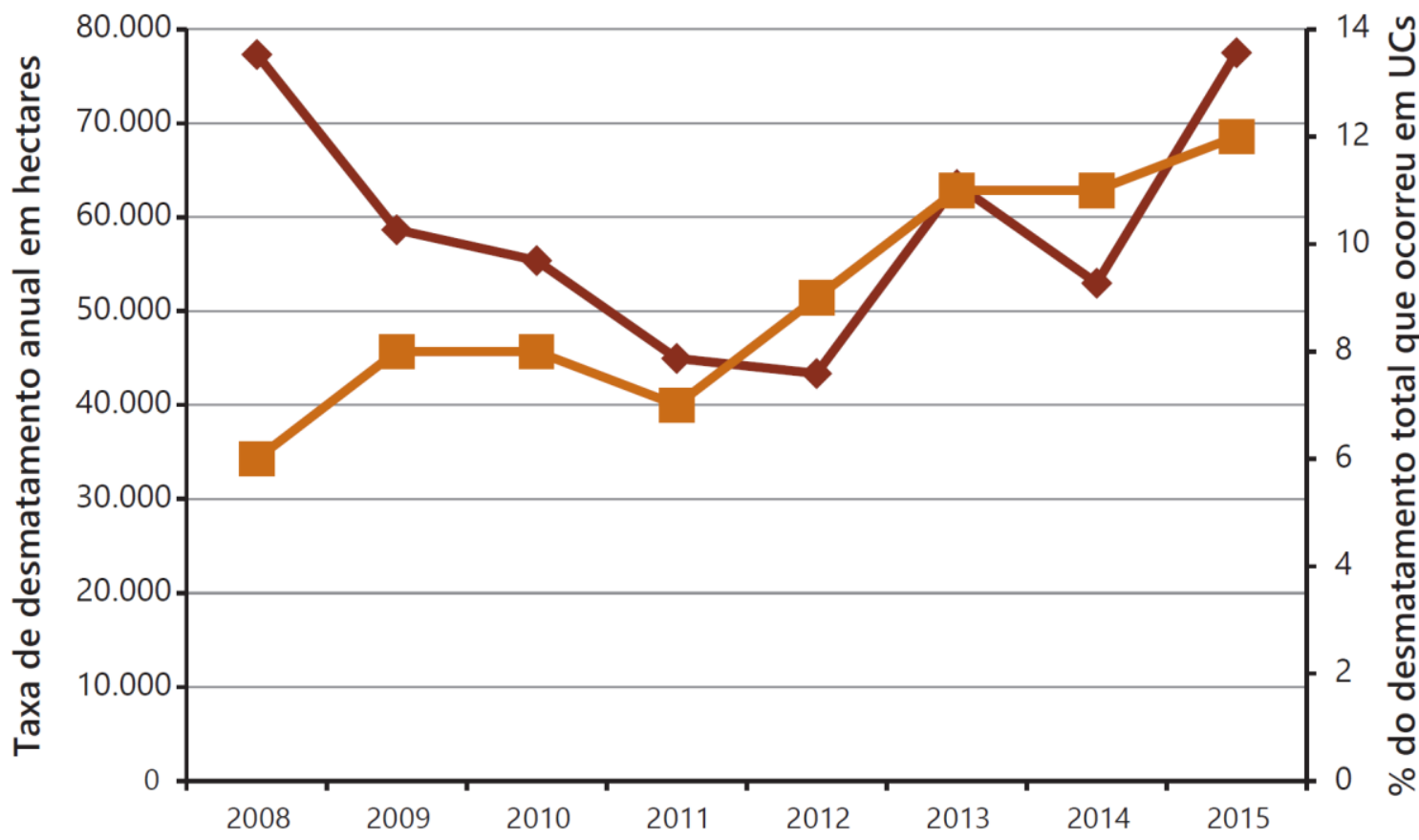

Fonte: Inpe, 2016 apud Araújo, 2017.

Projeto 3. Compostagem de resíduos orgânicos: reaproveitamento de resíduos domésticos em pequena escala

A compostagem doméstica (Figura 4) se mostrou viável para a reciclagem de resíduos sólidos orgânicos domiciliares, no entanto, o período de 45 dias não foi suficiente para a maturação total do composto. $O$ composto orgânico elaborado em 45 dias mostrou uma boa qualidade, porém, as folhas secas não sofreram total decomposição, sendo assim, necessário aguardar um período de mais 10 dias para a decomposição total 
das folhas e finalizar o processo. Outra possibilidade, poderia ser antes de iniciar a realização da mistura para a compostagem, proceder com a trituração das folhas secas, facilitando o processo de decomposição. Além disso, é necessário considerar a relação carbono e nitrogênio $(C / N)$ que interfere no tempo de compostagem dos materiais orgânicos.

Enfim, conclui-se que a experiência originou um composto com boas características físicas, não apresentando mau cheiro e com boa aparência, com potencial para uso em olericulturas e jardins domésticos, como condicionador de solos e/ou como substrato para plantas.

FIGURA 4: Composteira doméstica
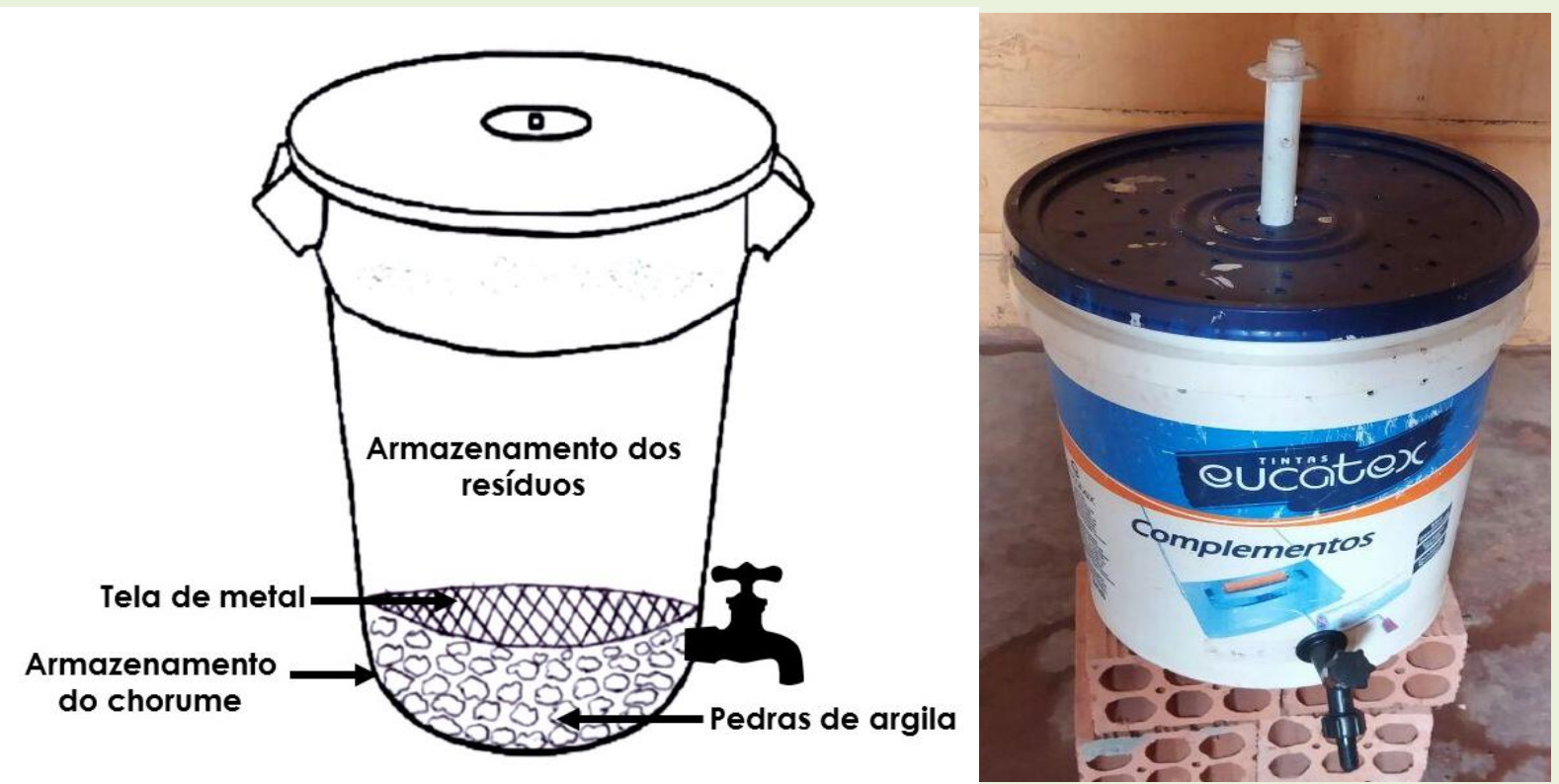

Fonte: Arquivo dos pesquisadores, 2017.

\section{Projeto 4. Percepção socioambiental dos moradores sobre as atividades} portuárias do distrito de Miritituba na cidade de Itaituba/PA

O distrito de Miritituba no Pará (Figura 5), localizado às margens do Rio Tapajós foi escolhido para a instalação do complexo portuário, essa logística destinada a receber os grãos de soja advindos do Centro-Oeste, principalmente do Estado do Mato Grosso, que chegam a Miritituba transportados por uma infinidade de caminhões, que rasgam a floresta Amazônica pela rodovia BR-230, mais conhecida como a Transamazônica e 
pela BR- 163 - Cuiabá-Santarém, certamente trouxe marcas de um progresso, mas junto com ele, o aumento dos impactos ambientais e sociais para a população do distrito de Miritituba.

A percepção dos moradores que participaram da pesquisa, em sua maioria, identificou e enumerou os impactos ambientais como: a qualidade da água; a poeira, causadas pelo grande fluxo caminhões; a poluição sonora; falta de tratamento de esgoto e a questão com os resíduos sólidos. A população sofre muito com a poeira no período do verão, mas não é diferente, na época do inverno, o problema continua com a lama. São problemas constantes enfrentados pela população, mas a maior preocupação é com a questão da higiene e saúde. Percebe-se uma insatisfação da população e ao mesmo tempo, uma preocupação com o futuro da cidade, pois não percebem vontade política para a solução dos problemas.

A população entrevistada demonstrou um misto de alegria e tristeza, ao mesmo tempo que estão contentes com a perspectiva promissora, retornam à realidade diária de suas experiências cotidianas.

FIGURA 5: Distrito de Miritituba município de Itaituba/PA

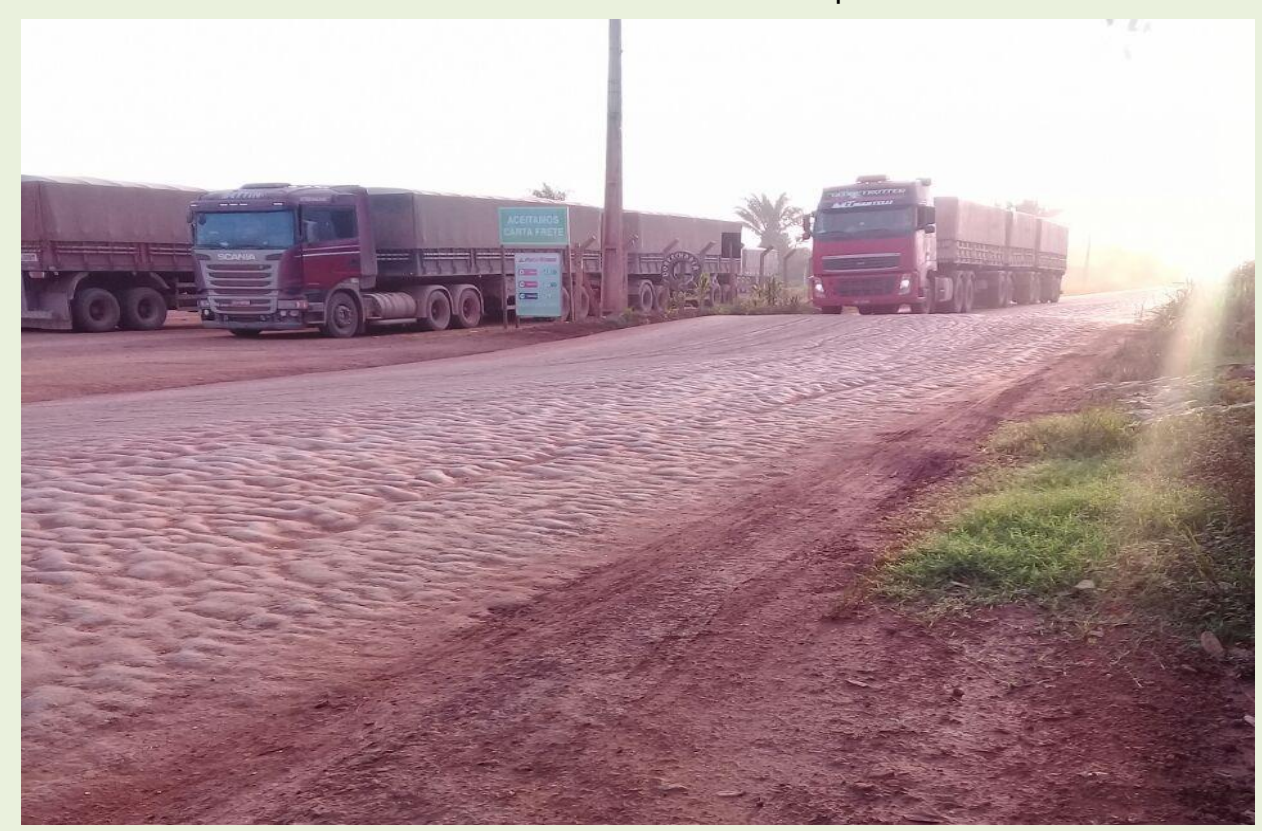

Fonte: Arquivo dos pesquisadores, 2017. 


\section{Projeto 5. Análise das oportunidades recreativas do Parque Nacional da Amazônia e comunidades do entorno}

Em relação ao objetivo deste trabalho, que buscou analisar o rol de oportunidades recreativas existentes no Parque Nacional da Amazônia (Figura 6) e comunidades do entorno, observa-se que os Parques oferecem um conjunto de possibilidades de recreação e de educação, necessitando de algumas intervenções como, por exemplo, uma empresa para atuar diretamente no fornecimento de uma estrutura e equipamentos para as atividades possíveis de serem realizadas dentro do parque e seu entorno. Por meio dessa intervenção, os atrativos turísticos do município teriam a possibilidade de receber um número maior de visitantes e com isso, possibilitar a geração de renda e contribuir com a economia local e/ou a custear a manutenção da própria Unidade de Conservação.

Não há dúvidas de que as áreas naturais devem ser preservadas para que existam, no futuro, espaços não modificados, e estes sejam utilizados para as práticas das atividades recreativas e turísticas. Para que isso aconteça, necessita haver um planejamento consciente. Este planejamento se faz necessário para evitar que os impactos ambientais sejam gigantescos sobre os meios visitados e manter a atratividade dos recursos para o futuro.

As áreas protegidas constituem-se em um dos principais instrumentos para garantir a continuidade de espaços naturais primitivos, ou seja, sem a ação do homem, e sua importância baseia-se em preservar estes espaços, para a qualidade de vida das gerações futuras.

Enfim, espera-se que este estudo, incentive as pessoas, principalmente os moradores locais, a conhecer e a usufruir de suas riquezas naturais e culturais em Unidade de Conservação, onde as pessoas possam realizar a prática do lazer e do ecoturismo, aliadas a conservação da natureza por meio da Educação Ambiental. 
FIGURA 6: Parque Nacional da Amazônia

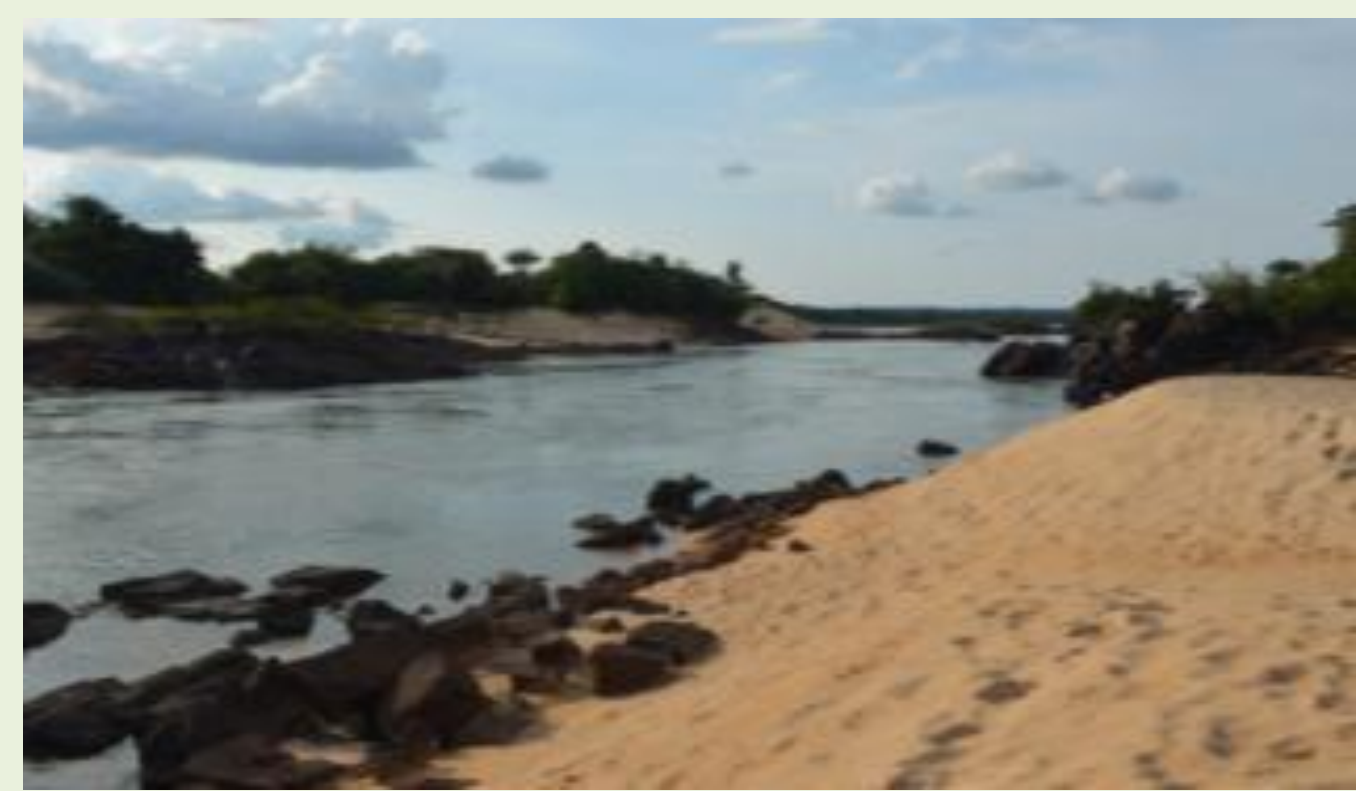

Fonte: Arquivo dos pesquisadores, 2017.

Projeto 6. Levantamento da percepção sobre as condições de saúde e segurança dos trabalhadores de serviços gerais em instituições de ensino na cidade de Itaituba-Pará

Com base nos resultados obtidos por meio do levantamento de questionários, notou-se que, os empregadores das instituições itaitubenses estão se preocupando com os seus funcionários com relação à saúde, e também, quanto aos materiais de segurança (Figura 7) e higienização. Desta forma, o estudo realizado nas instituições de ensino do município de ItaitubaPA, possibilitou verificar que os funcionários sempre recebem instruções e informações no início de seus contratos e que existe uma preocupação com relação à saúde. Mas, pôde-se constatar que ainda existe a falta de alguns equipamentos de proteção importante em suas atividades.

No entanto, percebe-se que os funcionários têm conhecimentos a respeito da saúde e segurança, mas se sentem insatisfeitos com relação ao quesito equipamentos de segurança. Sendo assim, é necessário que haja um comprometimento por parte dos empregadores, em proporcionar aos empregados todos os equipamentos de segurança e que estes estejam cientes de seu uso para diminuir os riscos com acidentes e promover a proteção à saúde e segurança. 
Contudo, esse trabalho traz o resultado de um conjunto de análise sobre várias situações ou condições, que são potencialmente desestabilizadoras, em razão de incongruências ou falta de adaptação entre pessoas e ambiente, causando problemas de saúde física ou emocional e ainda de alterações de comportamento no trabalho.

FIGURA 7: EPI= Equipamentos de Proteção Individual
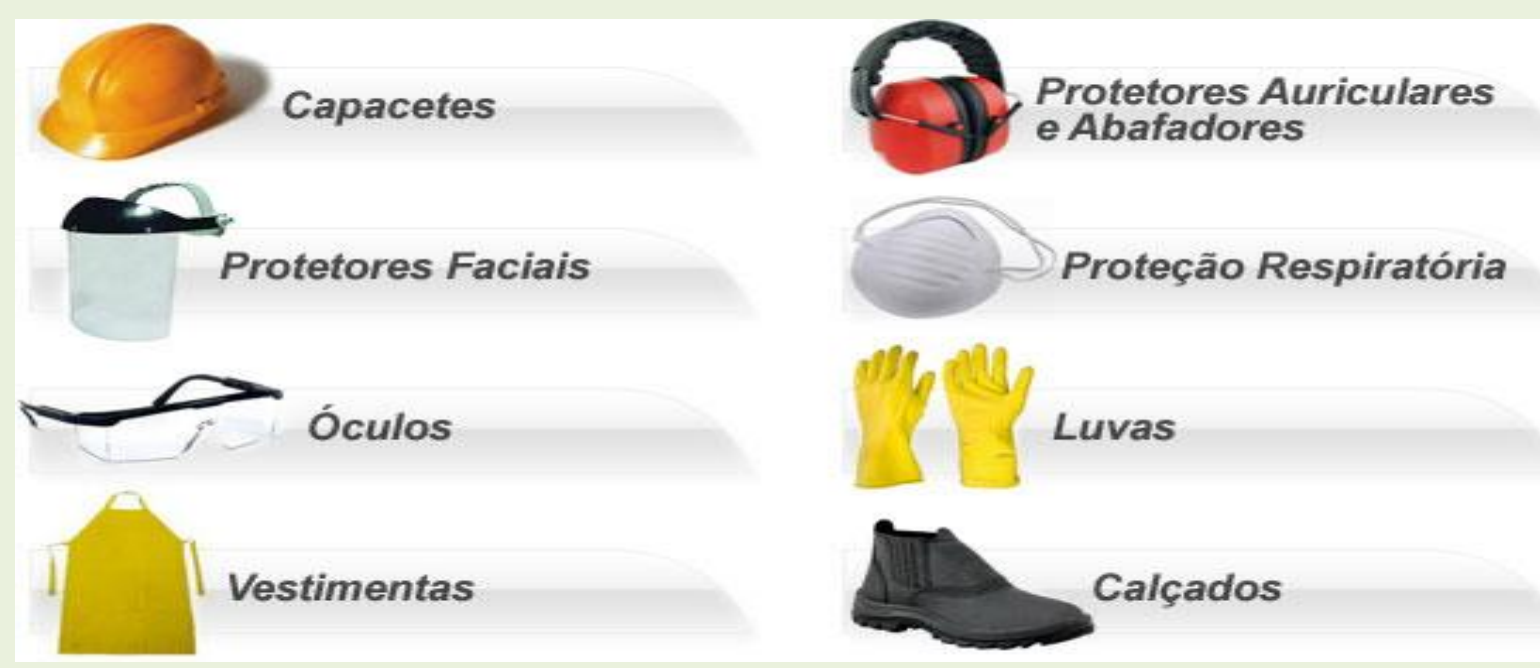

Fonte: Saraiva, 2014.

Projeto 7. As condições de saneamento e seus impactos à saúde pública dos moradores de palafitas do bairro Jardim das Araras, município de ItaitubaPará

A pesquisa realizada teve como ênfase proporcionar um levantamento de dados, a respeito das condições de vida que os moradores de palafitas, localizados no Bairro Jardim das Araras, tendo em vista que é uma área onde a população vive de forma aglomerada, em casas de madeira, acima do rio e passam por uma dificuldades habitacionais.

Neste levantamento, pôde-se constatar a necessidade dos moradores daquela localidade pela falta de saneamento básico e pela condição de habitação em que os mesmos se encontram. Durante a pesquisa, moradores afirmaram que foram morar naquela localidade, pela falta de estrutura, falta de emprego, falta de condições financeiras para comprar uma casa ou por 
não terem mais condições de pagar aluguel. Afirmaram também que sentem a necessidade de ruas mais abertas e pavimentadas, para facilitar o acesso deles em suas moradias.

A falta de saneamento foi um dos quesitos mais abordados pelos moradores, em detrimento das condições habitacionais em que vivem. Afirmaram ainda, sentirem a falta dos agentes comunitários de saúde mais presentes, as ruas não pavimentadas, fazem com que o acesso até as casas seja mais difícil, e as pontes suspensas sobre o rio trazem insegurança aos moradores e principalmente para as crianças que fazem desse espaço, o seu lugar de lazer.

Além do exposto, observou-se que os moradores das palafitas Jardim das Araras, em Itaituba vivem em condições precárias, percebeu-se que a falta de saneamento é evidente e que necessitam de ações públicas, para resolver a situação de saúde, higiene e moradia daquelas pessoas proporcionando Ihes condições de vida mais digna.

FIGURA 8: Palafitas do bairro Jardim das Araras, município de Itaituba-Pará

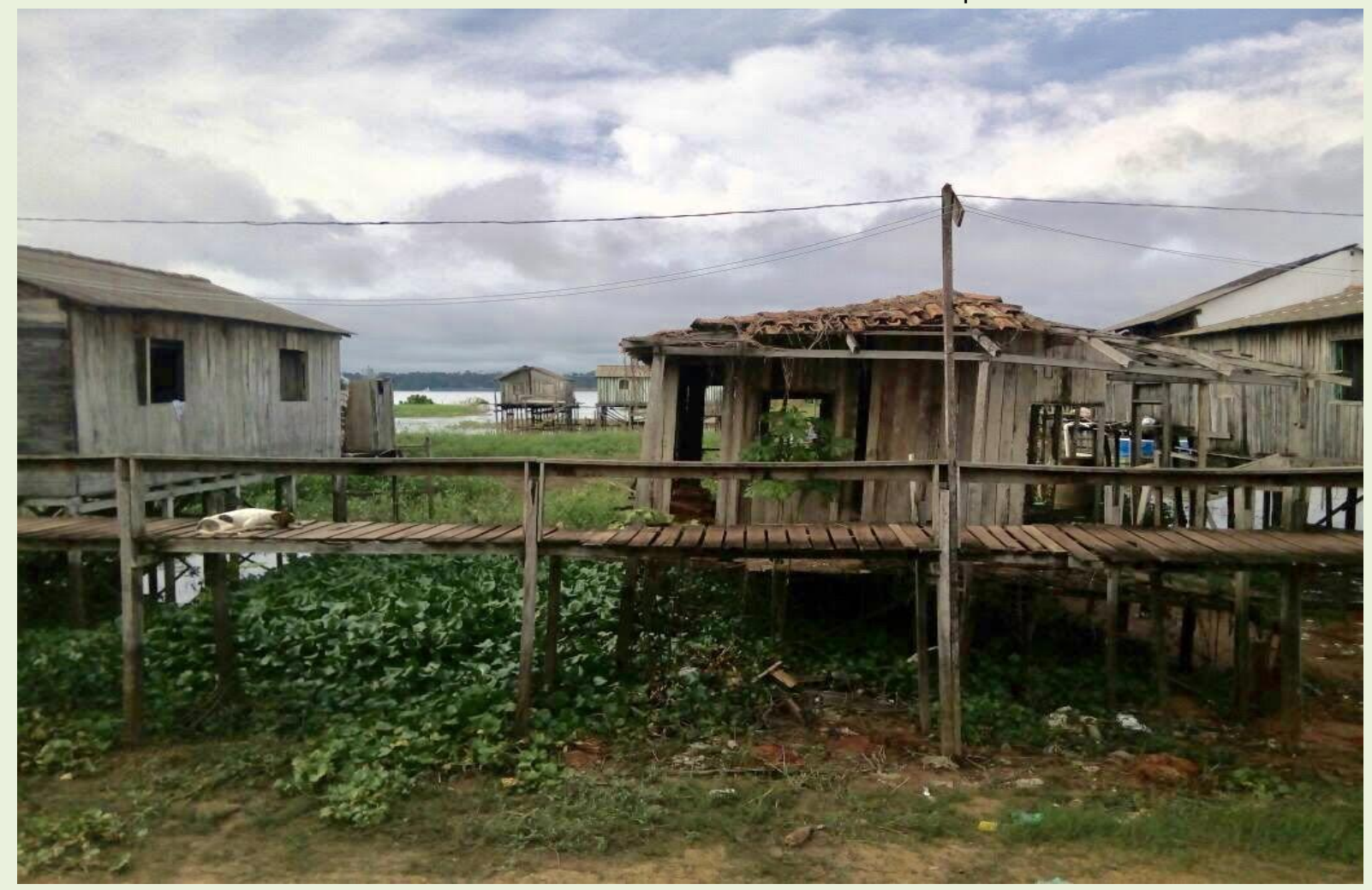

Fonte: Arquivo dos pesquisadores, 2017. 


\section{Projeto 8. O gerenciamento de resíduos de serviço de saúde no hospital municipal de Itaituba}

O hospital municipal de Itaituba fora construído há mais de 4 décadas, em um momento em que as legislações atuais, pertinentes a hospitais, não estavam em vigência. Assim, observa-se que o hospital busca adequar as estruturas de atendimentos da melhor forma possível.

Observou-se que o Plano de Gerenciamento de Resíduos de Serviço de Saúde - PGRSS - encontra-se em fase de adequação aos padrões estabelecidos pela legislação vigente, ao que se refere a essa questão, percebeu-se que estão sendo realizados estudos e levantamentos de dados para a elaboração do próprio plano de gerenciamento de resíduos de serviço de saúde, pois não disponibiliza de nenhum plano ou projeto de manejo desses resíduos, restando apenas as orientações aos funcionários quanto ao manejo e descarte.

Considerando que o estabelecimento gerador deverá ter controle através de ações gerenciais claras, funcionais, viáveis a sua realidade, assim como, instruídas aos profissionais envolvidos nesse processo, sobre as rotinas de cada setor. O hospital municipal de Itaituba busca priorizar a situação de controle de infecção hospitalar, que é estabelecida por legislação, conforme a Resolução RDC 306 de 7 de dezembro de 2004 da Agência Nacional de Vigilância Sanitária (ANVISA, 2004), que dispõe sobre o Regulamento Técnico para o gerenciamento de resíduos de serviços de saúde, o qual torna obrigatório esse gerenciamento em atividades de atendimento à saúde, entendendo que o correto trato dos resíduos, dentro desses estabelecimentos, reduz a possibilidade de contaminação cruzada aos pacientes, na gestão hospitalar o gerenciamento dos resíduos é visto como ferramenta administrativa essencial, ao controle de infecções hospitalares e assim, como garantia de uma prestação de serviço de qualidade à comunidade. 
FIGURA 9: Tipo e forma de descarte dos resíduos de serviços de saúde
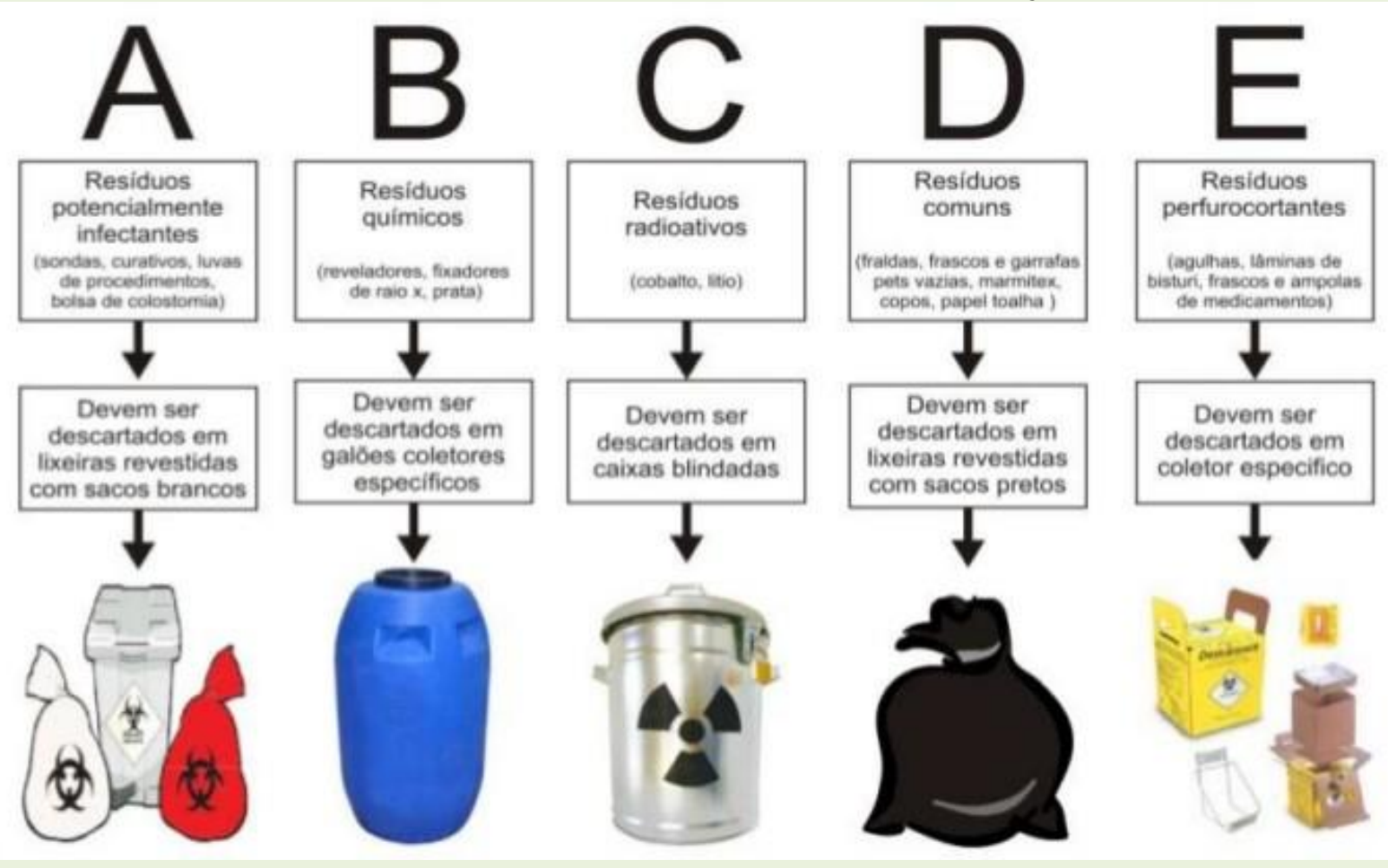

Fonte: Wons, 2017.

Projeto 9. Revitalização do espaço beira rio: promovendo a educação ambiental

Há muito tempo existe uma profunda preocupação com o descarte de resíduos em locais inapropriados, por causa destes fatores, constatou-se que foi de fundamental importância, realizar esta ação no espaço beira rio, devido ao elevado grau de polvição.

Foi necessário realizar-se uma grande limpeza (Figura 10), fixar lixeiras e placas de conscientização, com essa ação, investiu-se no processo educativo especial de Educação Ambiental para a população. Além dessa ação formativa, buscou-se realizar a limpeza do grande volume de resíduos localizados em várias partes da praia, em especial, da retirada do matagal, que dificultava a movimentação por toda a extensão da praia, sem contar que foram encontrados inúmeros objetos cortantes e perfurantes, que podem causar riscos para os banhistas, como pedaços de vidros, pregos, dentre outros. 
FIGURA 10: Limpeza do espaço beira-rio

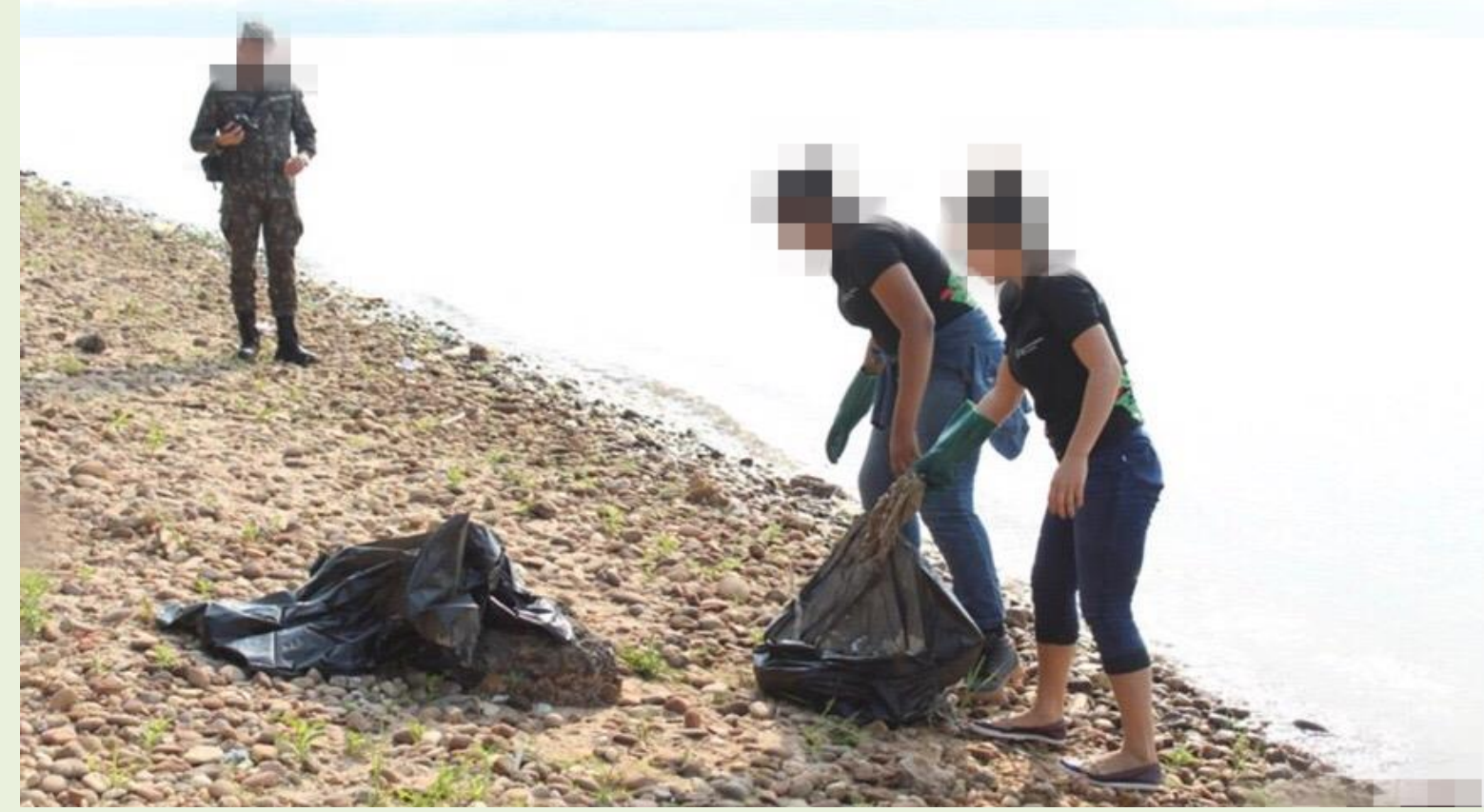

Fonte: Arquivo dos pesquisadores, 2017.

\section{CONSIDERAÇÕES FINAIS}

Este artigo buscou descrever os aspectos mais relevantes acerca da realização dos Projetos Integradores, nos $1^{a}, 2^{\circ}$ e $3^{\circ}$ períodos do curso Tecnologia em Saneamento Ambiental, como uma primeira experiência efetiva no Campus Itaituba do IFPA. Percebe-se, que muitos ajustes deverão ser implementados, na continuidade de realização dessa ação pedagógica, porém, os resultados alcançados foram significativos e contribuíram para a formação do aluno e possibilitou aos professores, a oportunidade de partilhar e receber conhecimentos. Na certeza de realização de novos Projetos Integradores, que serão implementados, a partir da efetivação da matriz curricular do curso, nos resta afirmar que o êxito e a contribuição para o conhecimento, não nos deixam dúvidas pelo sucesso desta primeira experiência, e quem sabe, Como incentivo para outras experiências, para outros cursos dentro e fora do Campus.

A elaboração e execução dos projetos integradores foi uma experiência exitosa, pois conseguiu integrar uma estratégia de ensino e 
aprendizagem eficiente. Os projetos desenvolvidos pelos alunos revelaram-se como um recurso complementar a formação tecnológica profissional, com o intuito de os alunos se beneficiarem de um ambiente de aprendizagem propício ao desenvolvimento de habilidades e competências usualmente pouco frequentes em sala de aula.

Dessa forma, a participação dos alunos e professores, ao trabalharem de maneira interdisciplinar, desenvolvel diversas competências, articulando conteúdos e aprendizagens e proporcionou ao estudante a possibilidade de pôr em prática, os conhecimentos teóricos já apreendidos, incentivando-os a trilhar os caminhos da pesquisa mesmo que de forma incipiente. Constatou-se que os Projetos Integradores aprimoram a produtividade escolar, o engajamento do aluno em fazer pesquisa, o olhar social da pesquisa acadêmica e formação para a cidadania, em uma visão emancipadora, transformadora e de reflexão sobre a própria prática.

Outro fator interessante, é que ao trabalhar com alunos a partir deste ponto de vista, a motivação é perceptível, o que nos leva a supor, que essa metodologia poderá ser uma ferramenta que incidirá diretamente na política de permanência e êxito, evitando com que ocorra a evasão. Desta forma, acredita-se que a memória do processo educativo abordado neste artigo é de fundamental importância para a continuidade dos trabalhos. Como já nos ensinava Freire (2006, p. 35), que os processos pedagógicos exigem envolvimentos dinâmico entre o ontem e o hoje, entre o fazer e 0 fazer pensar, e a efetivação de conhecimentos construídos. Assim, acreditase que esta ação pedagógica se torne mais frequente nos cursos do Instituto Federal do Pará em especial no Campus Itaituba, e quiçá, seja referência a todos os educadores interessados a contribuir com uma educação capaz de romper as barreiras e se tornar de forma diferenciada, para a efetivação da autonomia nos processos acadêmicos.

\section{REFERÊNCIAS}

AGÊNCIA NACIONAL DE VIGILÂNCIA SANITÁRIA - ANVISA. Resolução da

Diretoria Colegiada da ANVISA - RDC 306. 2004. Disponível em: 
http://portal.anvisa.gov.br/documents/33880/2568070/res0306_07_12_2004.p df/95eac678-d441-4033-a5ab-f0276d56aaa6. Acesso em: 23 set. 2017.

ARAÚJO, E. et al. Unidades de conservação mais desmatadas da Amazônia Legal 2012-2015. Belém, PA: Imazon, 2017. Disponível em: http://imazon.org.br/PDFimazon/Portugues/livros/UCS\%20mais\%20desmatada s\%20Amazonia_2012-2015.pdf. Acesso em: 23 set. 2017.

BRASIL, Diretrizes Curriculares Nacionais Gerais para a Educação Básica. Ministério da Educação. MEC, SEB, DICEl, 2013. 524p. Disponível em: http://www.portal.mec.gov.br/docman/julho-2013-pdf/13677-diretrizeseducacao-basica-2013-pdf/file. Acesso em: Acesso em 14 jan. 2018.

CANDAU, V. M. A didática e a formação de educadores - da exaltação à negação: a busca da relevância. In: A didática em questão. Petrópolis, RJ: Vozes, 2007.

FAZENDA, I. C. A. et al. Avaliação e interdisciplinaridade. R. Interd. São Paulo, v.1, n. 0, out, 2010. p. 01-83. Disponível em:

https://revistas.pucsp.br/index.php/interdisciplinaridade/article/viewFile/1614 2/12179. Acesso em: 01 jan. 2018.

FAZENDA, I. C. A. Integração e interdisciplinaridade no ensino brasileiro: efetividade ou ideologia. 6. ed. São Paulo: Loyola, 2011. Disponível em: http://www.pucsp.br/gepi/downloads/PDF_LIVROS_INTEGRANTES_GEPI/livro_i ntegracao_interdisciplinaridade.pdf. Acesso em: 01 nov. 2017.

FAZENDA, I. C. A. Interdisciplinaridade: qual o sentido? São Paulo: Paulus, 2003.

FAZENDA, I. C. A. Interdisciplinaridade: história, teoria e pesquisa. 9. ed. São Paulo: Papirus, 2002.

FREIRE, P. Pedagogia da autonomia: saberes necessários à prática educativa. 34. ed. São Paulo: Paz e Terra, 2006.

INSTITUTO FEDERAL DE EDUCAÇÃO, CIÊNCIAS E TECNOLOGIA DO PARA - IFPA. Projeto político pedagógico do curso Tecnologia em Saneamento Ambiental, Campus Itaituba/IFPA. Itaituba: [s.n.], 2012.

JAPIASSÚ, H. Interdisciplinaridade e patologia do saber. Rio de Janeiro: Imago, 1976.

LIBÂNEO, J. C.; OLIVEIRA, J. F. de; TOSCHI, M. S. Educação escolar: políticas, estruturas e organização. 10. ed. rev. e ampl. São Paulo: Cortez, 2012. (coleção docência em formação: saberes pedagógicos).

LIBÂNEO, J. C. Didática. 2. ed. São Paulo: Cortez, 2013. 
MARANGONI, C.; MOURA, N. F. de; GARCIA, F.R. M. Utilização de óleos essenciais e extratos de plantas no controle de insetos. Revista de Ciências Ambientais, Canoas, v. 6. 2, p. 95-112, 2012. ISSN 1981-8858.

MARINHO, A. M. S. A educação ambiental e o desafio da

interdisciplinaridade. 2009. 117 f. Dissertação (Mestrado em Educação) Pontifícia Universidade Católica de Minas Gerais. Belo Horizonte, 2004.

RAJADELL, N. A importância das estratégias didáticas em toda a ação formativa. In: SUANNO, M. V. R.; PUIGGRÒS, N. R. (org.). Didática e formação de professores: perspectivas e inovações. Goiânia: CEPED e PUC Goiás, 2012.

SARAIVA, R. EPI pode ser obstáculo de aposentadoria especial. Recife, set. 2014. Disponível em:

http://blogs.diariodepernambuco.com.br/espacodaprevidencia/epi-podeser-obstaculo-da-aposentadoria-especial/. Acesso em: 25 set. 2017.

VALÉRIO, R. A. O que é leitura? Uma investigação interdisciplinar. 2009. 233 f. Tese (doutorado em Linguística Aplicada e Estudos da Linguagem) Pontifícia Universidade Católica de São Paulo, São Paulo, 2009.

VARELLA. A. M. R. S. A resiliência e a interdisciplinaridade. R. Interd. São Paulo, Volume 1, número 0, p. 01-83, out, 2010. Disponível em: http://http://revistas.pucsp.br/index.php/interdisciplinaridade/issue/view/103 9. Acesso em: 01 nov. 2017.

WONS, F. Plano de gerenciamento de resíduos de serviços de saúde - PGRSS. Licenciador ambiental. [s.l.], jun. 2017. Disponível em: http://licenciadorambiental.com.br/plano-de-gerenciamento-de-residuosde-servicos-de-saude-pgrss/. Acesso em: 25 set. 2017.

Recebido em: 16 de junho de 2018. Aprovado em: 15 de fevereiro de 2019. 